\title{
Intraductal biliary polypectomy performed with a nasogastroscope
}

Authors

Institutions
Anne Druez ${ }^{1}$, Elizaveta Kim², Christine Sempoux ${ }^{3}$, Pierre Deprez ${ }^{2}$

${ }^{1}$ CHU Dinant Godinne UCL Namur - Gastroenterology, 1, avenue Dr. G. Thérasse, 5530 Yvoir, Belgium

${ }^{2}$ Cliniques Universitaires St-Luc - Hepato-Gastroenterology, Brussels, Belgium

${ }^{3}$ Cliniques Universitaires St-Luc - Pathology, Brussels, Belgium submitted 3. April 2014 accepted 22. April 2014

\section{Bibliography}

DOI http://dx.doi.org/

10.1055/s-0034-1377174

Published online: 6.6.2014

Endoscopy International Open

2014; 02: E124-E125

(c) Georg Thieme Verlag KG

Stuttgart · New York

E-ISSN 2196-9736

\section{Corresponding author}

\section{Anne Druez}

CHU Dinant Godinne UCL

Namur - Gastroenterology

1, avenue Dr. G. Thérasse

5530 Yvoir

Belgium

Fax: 003281423267

druez.anne@gmail.com
Abstract: We report the first case of intraductal biliary polypectomy performed with a nasogastroscope.

\section{Introduction $\nabla$}

A 79-year-old man was admitted to emergency for septic shock due to angiocholitis, with acute renal failure, hyperlactatemia, and thrombopenia. His medical history included a cholecystectomy for acute cholecystitis and removal of choledocholithiasis that occurred more than 10 years ago.

\section{Case report \\ $\nabla$}

Computed tomography confirmed the recurrence of cholelithiasis in the common bile duct (CBD) and in the dilated right hepatic duct associated with atrophy of S6-7 hepatic segments ( $\bullet$ Fig. 1). Multiple stones and pus were extracted from the CBD during endoscopic retrograde cholangiopancreatography, which revealed a tight stricture, which could not be bypassed using several guide wires and upstream dilation, and intraductal stones in the right hepatic duct. The duodenoscope was therefore replaced by a nasogastroscope (GIF-N180, Olympus) introduced with a $50 \mathrm{~cm}$ overtube for stability, to allow visualization of the site of stenosis and removal of the stone in the right hepatic duct ( Fig.2). A $6 \mathrm{~mm}$ polyp (Paris $0-1 \mathrm{sp}$ ) ( $\bullet$ Fig. 3 ) was visualized below the stricture and was removed using a diathermy snare (SD-221L-25, Olympus) ( Fig. 4). This was followed by several targeted biopsies of the biliary stricture. Scopes were exchanged over a $0.035 \mathrm{Jag}$ wire to dilate the stricture using a $6 \mathrm{~mm} \times 4 \mathrm{~cm}$ Hurricane balloon, to extract pus and stones, and to place a 7-Fr plastic biliary stent. Histology showed no malignant cells, but revealed an inflammatory infiltrate in the biopsies and a fibroinflammatory polyp. During follow-up that lasted almost two years, the patient's progress was favorable, the stent was left in place for more than one year, and he experienced no recurrent cholangitis. 


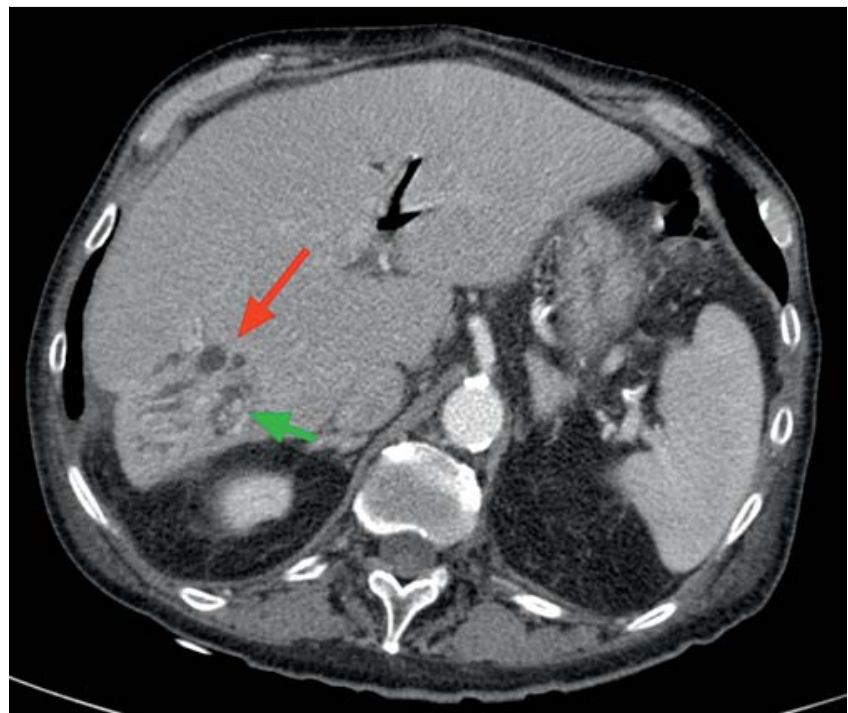

Fig. 1 Abdominal computed tomography scan showing the dilated right intrahepatic ducts with intraductal stones.

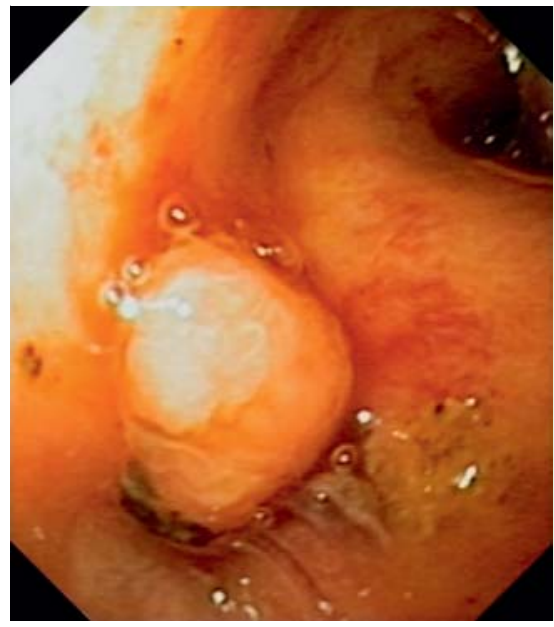

Fig. 3 Cholangioscopic view of the polyp below the duct stricture.

\section{Discussion}

This case report illustrates the feasibility of biliary intraductal polypectomy during cholangioscopy performed with a nasogastroscope.

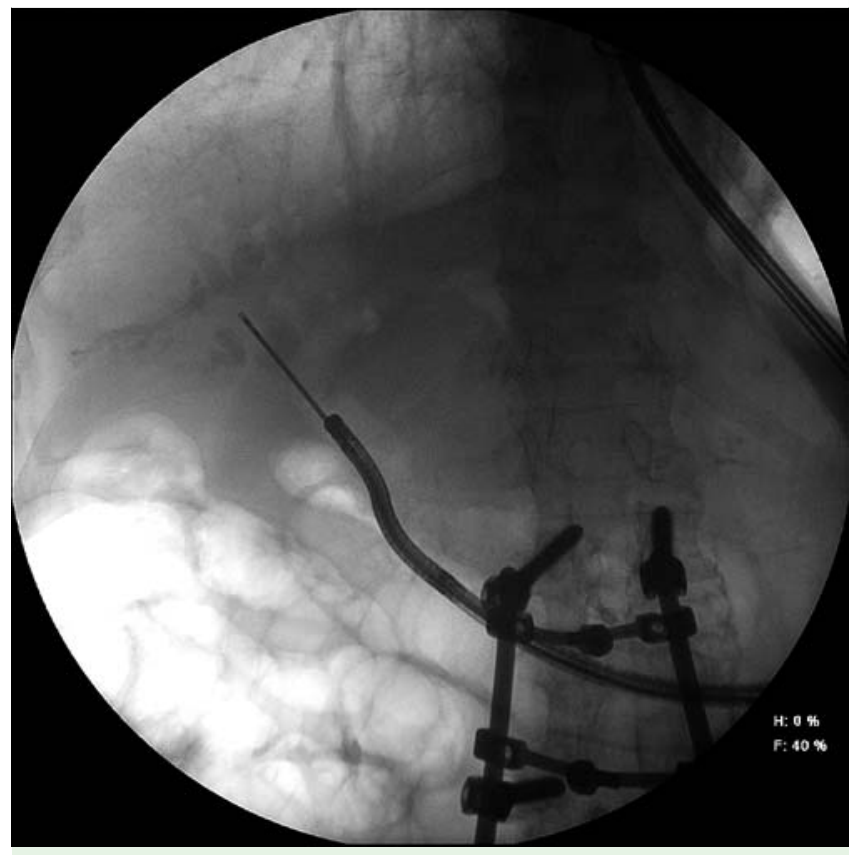

Fig. 2 Fluoroscopy showing the position of the nasogastroscope and the biopsy forceps in the right hepatic duct.

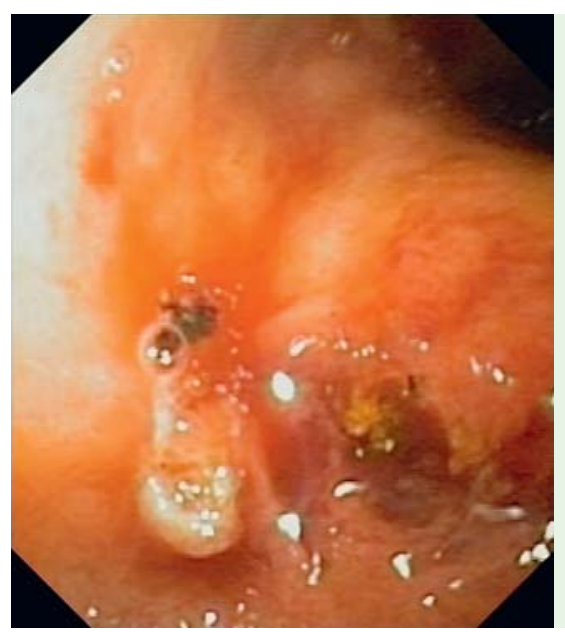

Fig. 4 Cholangioscopic view of the post-polypectomy site.

\section{Abbreviations}

CBD common bile duct

Competing interests: None 